\title{
Value creation for IoT: Challenges and opportunities within the design and development process
}

\author{
Boyeun Lee*, Rachel Cooperi ${ }^{\dagger}$, David Hands ${ }^{\#}$, Paul Coulton ${ }^{\wedge}$ \\ *Lancaster University,UK, and b.lee12@lancaster.ac.uk, ${ }^{\dagger}$ Lancaster University,UK and r.cooper@lancaster.ac.uk, \\ \#LancasterUniversity,UK and d.j.hands@lancaster.ac.uk, ^Lancaster University,UK and p.coulton@lancaster.ac.uk
}

Keywords: Internet of Things, design and development process, value creation for IoT, Risks in IoT development, SPHERE project.

\begin{abstract}
IoT initiatives look promising and straightforward, but they are far more complicated to enact as it stands today. Although developing digitised artefacts offers a rich new set of value creation and growth opportunities to organisations, to grab these opportunities encompass a wide variety of strategic risks. In this context, in academia, little attention has been focused on NPD processes, development risks and value creation in IoT. Thus, this paper offers a discussion on what development risks are found, what is new approach to NPD process, and how value for IoT is created comparing its counterpart in traditional manufacturing economy. To achieve this aim, a literature review was undertaken to examine existing value creation and NPD models, which are continuously evolving but not much improved in their application to developing digitalised artefacts. Through a case study, the risks, opportunities and activities for IoT development are further elaborated and critically discussed. Finally, along with a discussion of the strategic development challenges and opportunities, a continuous process of a new NPD model for IoT products and services is proposed.
\end{abstract}

\section{Introduction}

The Internet of Things (IoT) was comprised of 15 billion devices in 2015 and will reach over 30 billion units by 2020 , equivalent to 3 smart objects for every human on Earth [1]. The IoT has heralded smart and more efficient living, affecting business, manufacturing, healthcare, retail, security and transport. The IoT consists of sensor-embedded devices that use wireless technology to talk to one another, to users and to environment. It is transforming every aspect of modern living, industry and the economy. According to recent analyses on emerging technologies, the total global impact of IoT technologies could generate anywhere from $\$ 2.7$ trillion to $\$$ 14.4 trillion in value by $2025[2,3]$.

There is the potential for revolutionising and creating market space for new products, service offerings and business models. With the emergence of the Internet of Things as a new source of data, businesses face new opportunities as well as novel challenges [4]. The IoT is regarded as a fertile field for commercial enterprises and that one in every six businesses is planning to roll out an IoT-based product [5]. However, it was shown that businesses implementing an IoT initiative had only 26 percent success rate [6]. The challenges such as the quality of the data, the internal expertise, the unexpected increased time to completion, mastering the network of smart 'things' which is far harder than businesses could have imagined slow the growth of IoT. Because these pervasive adoptions of digital technologies radically change traditional ways of business activities such as: how the supply chain operates [7]; how organisations develop new products and services [8]; how they create meaningful value [9]; and how risks in new product development process are managed.

However, despite growing popularity of the IoT, and the emergent opportunities and challenges to the adoption of the 'IoT', minimal attention has been focused on the New Product Development (NPD) process, which is arguably one of the most critical marketing planning and implementation process activities. Scholars from marketing and design argue that it is time to reframe traditional processes of product design and development to satisfy current needs and potential commercial opportunities in the era of IoT $[10,11]$.

With the significance of NPD process, the significance of risk management in NPD processes is emphasized in literature [12, $13,14,16,17]$. In product development in literature, risks are defined differently such as the possibility that an undesired outcome disrupts your project [17]; or as the possibility of suffering harm or loss due to an undesirable event [18]. Overall, risk can be identified as an unfavourable circumstance or condition that should be avoided or minimized for the success of a company's NPD. The product development risks are divided into two main categories regarding the source of risk: internal (identified as risk source within organisation) and external (risks that originate from the product development environment) [19]. Internal risks are usually controllable by the project management team while external risks cannot be controlled [20].

Risk management maximises opportunities and value whilst minimizing the threat of the business [12]. However, there is a paucity of established academic theories and industry practices about risk management for IoT products and services development. Managing risks over IoT design and development processes particularly challenges because IoT applications are complex systems with multifaceted architectural and abstraction layers.

This paper offers initial results of the early stages of doctoral research, which is to provide opportunities and challenges of the IoT design and development process in terms of increasing 
organisational value. Its primary aim is to contribute to an emergent understanding of IoT NPD processes and challenges involving opportunities for value creation. In order to achieve these aims, the following research questions will be both offered and critically debated:

1) How is traditional NPD processes and value creation different to its counterpart for IoT?

2) How are IoT products and services developed and what risks are identified during the development process?

3) How can the product development risks be managed effectively?

In order to answer these critical questions, this research study involves three primary qualitative research methods; these include conducting an extensive examination of current literatures, exploratory interviews and a comprehensive case study.

\section{Methodology}

As part of the literature review, books, articles and academic texts were selected through searching electronic databases such as Wiley Online Library Journals, ProQuest Business Premium Collection, Springer Journals Archive, and Google Scholar. Search terms used, included 1) "value chain", "value creation", "value constellation", "service dominant logic", "goods dominant logic", "Digital economies", and "Digital innovation", 2) "design and development process", "NPD", "NSD (New Service Development)", "Innovation process" and "NPD for IoT", 3) "development risks", "risks in NPD processes", "risk management", "risks in automotive development process", "risks in IoT development process". These were then supported by a manual investigation of abstracts and articles published in select journals- Proceedings of CHI, Journal of Product Innovation Management, Harvard Business Review, European Journal of Innovation Management, and Journal of Information Technology. Each text was critically examined for their relevance to the primary question(s) concerning the main research study.

A series of exploratory interviews were undertaken in order to investigate the subject area and develop ideas rather than to establish facts. Several semi-structured interviews were conducted lasting on average 45 minutes, between October and November 2017. Leading academics in the PETRAS project were selected for the in-depth interviews. Target interviewees were recruited for diversity with regard to their disciplinary backgrounds within the sample group. Interview questions were developed focusing on issues and themes about value creation for IoT, discrepancies in value creation between the traditional manufacturing economy and digital economies, and attendant issues around IoT development in general.

In order to investigate the inherent risks in value creation and NPD processes for IoT, the SPHERE project was selected as an initial case study, which forms part of a pilot study prior to successive larger case-study activities. The case study was achieved through a series of semi-structured interviews and engagement tools lasting up to two hours in July 2018. Recruitment criteria for participants for the case study included experts who have knowledge and practical experience in IoT for over 10 years; who have a detailed understanding of the whole process of IoT products and services development; and who hold the authority to drive the project and make strategic decisions. The interviews were recorded, transcribed, coded and analysed for themes that were then clustered into defined categories and then compared across interviews, data from engagement tools and the literature review.

\section{IoT, triggering radical transformation in business activities}

\subsection{Traditional NPD processes and value creation}

The term, New Product Development (NPD) is defined in a large number of literatures. Ulrich and Eppinger [21] define NPD as the set of activities beginning with the perception of a market opportunity and ending in the production, sales and delivery of a product. Similarly, from engineering and business perspectives, Susterova et al. [12] identify NPD as the complete process of bringing a new product to market. Over the past fifty years, the terms have been defined variously, but the key theme could be identified as a complex business activity for the transformation of customer needs into organisational value through fascinating products and/or services in the market.

Within manufacturing economies, the conventional way to transform customer needs into organisational value is only to presume the dominant source of information about the market and customer needs, then to validate assumptions and test reactions to the products. Since the data surrounding use and experience is rare or costly in terms of access, customer's insights are easily ignored, and executive foresight is more influential and impactful. The process can be explained by the value chain model.

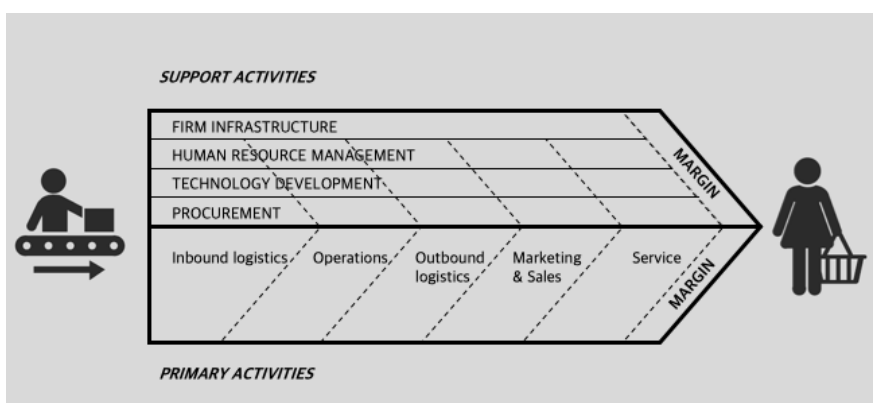

Fig. 1 The value chain model adapted from Porter and Millar [22]

In this conventional linear value chain model, value is often created without any co-creation contribution from customers [23]. Products are developed based on executive's insights and pushed to the market rather pulled by customer's needs, which is also known as a push economy. The product, after being sold, becomes obsolete and value of the product decreases over time. Consequently, companies are able to sell the next product and continue to make profits. The traditional NPD processes are similar to the value chain model, ie illustrated as linear models, such as stage-gate, over the wall process, or waterfall model. These are still the most commonly used models [20]. 

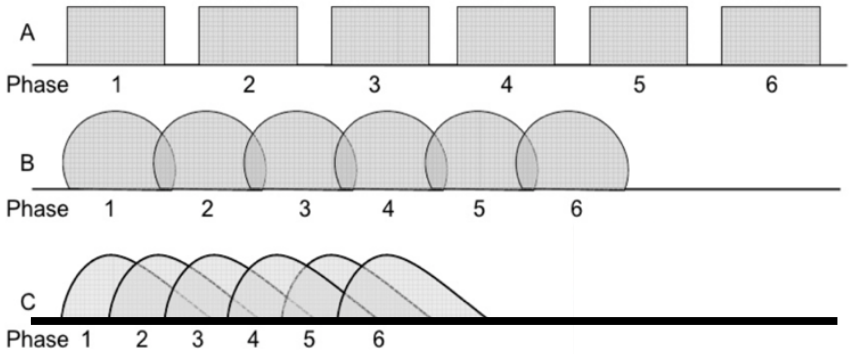

Fig. 2 (A) Sequential vs. (B and C) Overlapping. Phases of development. [26]

Under the sequential approach, the project moves sequentially from stage to stage, involving different organisational departments in each stage. Consequently, many companies have discovered that there are limitations to sequential processing which increase time and cost of product development. Therefore, based on considering the project as a whole and integrating functions [24, 25], simultaneous (rugby) approaches have emerged (e.g., parallel processing models [26]; Concurrent Engineering [27]; Activity-stage models [28]; Multiple convergent model [29]. This approach is proven to improve the speed of the development process and enables it to be accompanied by new philosophies of design, allowing products to be more adaptable and desirable to the customers [30].

In addition to the sequential and simultaneous approaches, there is diversity of NPD models that have evolved and been refined by researchers and practitioners, such as: Double diamond design process model which contains four distinct phases, Discover, Define, Develop and Deliver [31]; service design process which describes new service development sequence [32]; Chesbrough's open innovation model that emphasises co-work with outside a firm in relation to design and development activities [33]; Agile software development process which is based on iterative and incremental process [34].

Although, NPD models have evolved over the fifty years as reflected in the academic literature, they have in fact gone through relatively few changes, despite the dramatic market and technological changes, which have had tremendous impact on all aspects of our lives and business practices, design and development practices [35]. In digital economies, they are regarded obsolete, requiring entirely new approaches $[36,8$, $37,38]$. This is because the unique characteristics of digitalised artefacts enable more accurate and real-time visibility of the user context which transforms NPD processes as well as the approach to value creation. Therefore, the attention of this discussion focuses upon the key factors that are influencing value creation and the design process for IoT products and services and how they differentiate value creation and existing NPD processes.

\subsection{Factors influencing value creation for IoT}

Unlike traditional products which have a fixed, discrete set of boundaries and features, the dimensions of big data [39], the material properties of digitalised artefacts [37] and the characteristics of digital technologies [8] are changing the development of the product, service and indeed value creation. Reflecting these factors, the IoT makes it possible to interact in real-time with customers and incorporate changes in any phase of the value creation process. Specifically, having sensor-based things and the ability to collect data enables IoT to give support for both industry and customer driven value creation processes and, hence, be involved in a co-creative system [40].

The term value chain has now slowly but largely been superseded by a modified title- 'value constellation [41]' shown in Figure 3 which seems more applicable to the value creation in the IoT. Because unlike the typical NPD activities which are internally focused [42], value constellation describes the interplay between economic actors-suppliers, business partners, customers- and resources in order to coproduce value $[43,44]$. The increased complexity of developing IoT products and services often require expertise that the firm does not have; thus, activities of NPD processes for IoT should encompass interplay between diverse stakeholders.

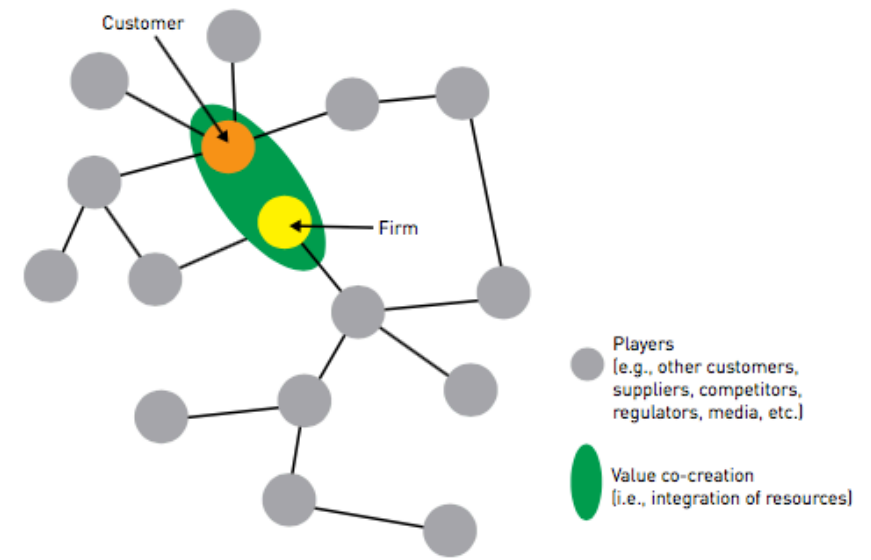

Fig. 3 A value constellation and the space of co-creation as described [11]

Scholars and practitioners have argued where the real value of the IoT comes from. According to Lee and Lee [45], IoT applications aimed at enhancing customer value are comprised of monitoring and control, big data and business analytics, as well as information sharing and collaboration. The fact that the value of IoT is created by data from the digitised artefacts [46, $47,4]$ is testified by the news that Google paid $\$ 3.2$ billion to buy Nest, a connected-home devices company. However, data can only be turned into value if it is a right resource to be used in the right context. As the fundamentals of the IoT lie within the idea of the interconnecting things, the true value of the IoT is thoroughly realised when more things are connected and able to communicate with each other seamlessly.

Developing digitised artefacts offers a rich new set of value creation and growth opportunities to organisations. However, efforts to gain these opportunities encompass the greatest strategic risks. Therefore, the paper will discuss further 'how' IoT products and services are designed and developed, and what risks reside over the NPD process based on the case study of SPHERE IoT development project. 
3 Risks and opportunities within IoT design and development process

SPHERE (Sensor Platform for Health in a Residential Environment) is a smart home system for monitoring residents' physical and mental wellbeing. The project has initiated within the context in which the number of people living longer with one or more chronic health condition is rising in the UK, and as such, future healthcare services in the UK should be set for a conversion from clinical setting into the home [48]. The SPHERE team had to develop a new IoT ecosystem including a series of products and services. The new product development processes (NPDs) for IoT and the risks during the process are discussed below.

1. Identifying customers' requirements

The process begins with identifying customers' requirements. In the SPHERE project, it was difficult to identify consumer requirements, as both the clinical researchers, customers were unfamiliar with IoT systems, and they did not know the opportunities and benefits it could give them. The risk at this stage is that customers generally are not trained to articulate and define their requirements so that it challenges the team to accurately define what their requirements are. Although they identify their requirements, they could be impossible, contradictory or badly defined.

At this phase, the SPHERE team developed a series of workshops and meetings, the format of which were based around conversation and brainstorming ideas. Beyond identifying and understanding what future customer requirements are, it was recognised that this first stage was very important for building strong relationships with the customers in order to prepare for commercialising or scaling the IoT system. Regarding the supplier and partner relationship in the NPD, having stronger relationships accounts for about one-third of the personnel hours advantage and contributes to four to five months' lead time advantage [25].

\section{Technical discussion}

The technical discussion phase revolves around the need to explore appropriate technology for the system. As it is argued that technical risks may be encountered in the majority of NPD process phases [20], this phase are likely to have a number of strategic decisions to be made. Technical risks that require strategic discussion in this phase would include what kind of system to develop; what level of smartness and intelligence the system would have; and whether to use labelled data. Whether the company identified the customers' requirement accurately, it could be diverse variety of ways to deliver value. Thus, strategic discussion is required in order to identify the system to develop. Regarding the issues of capabilities of smart, connected products, a company must choose the set of capabilities that deliver its customer value and define its competitive positioning [4].

Each capability is valuable in its own right as illustrated in figure 4 and depending on what level of smartness the product has, different risks would follow. The issue of labelled data is an interesting example. Using labelled data is cheaper and means financial resources can be deployed elsewhere; however, you might be challenged to differentiate your business to that of your competitors. Alternatively, deciding to build annotated data sets and testing the algorithm in-house costs more in terms of time and money.

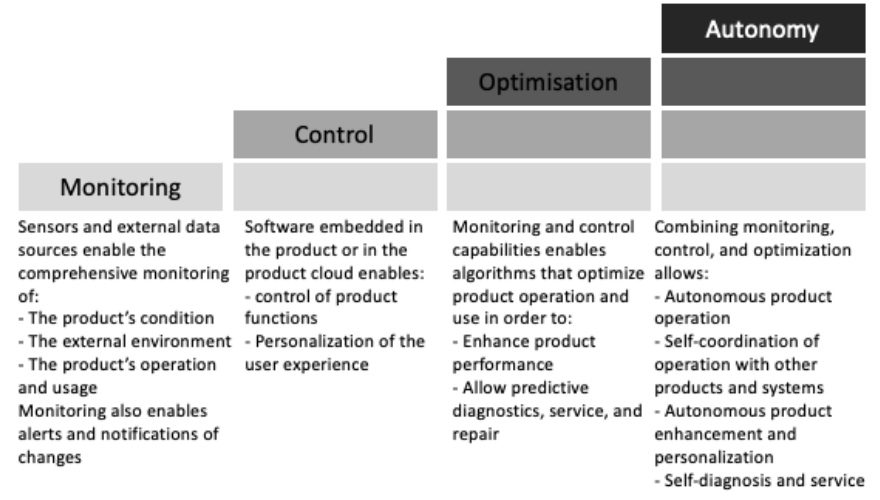

Fig. 4 Capabilities of smart, connected products [4]

Another risk discovered here is that of system performance, or rather not knowing the performance of the system until the system is actually developed and deployed. Therefore, the sensor prototype and development stage must follow very quickly in order to understand if the right decisions have been made. This is an important phase of development as identifying customers' requirements and going through technical discussion aided the researchers in discovering the overlaps between customers' needs and what was, ultimately, achievable. It is recommended to move quickly forward to the sensor prototype and development stage and make it real prior to full production.

3. Testing feasibility and acceptability, and sensor development

After the Technical discussion phase, the IoT system was installed into the Sphere House which is a physical space for the purpose of prototyping the system. The Sphere team used a combination of traditional ethnographic methods and participatory techniques in order to test feasibility and acceptability. 25 participants spent two weeks each living in the Sphere House and, during this time, how they used and perceived the system was monitored. At this point, the sensors had not been fully developed so that the Bristol university team used commercial sensors rather than their own. Thus, sensor development, the feasibility, and acceptability testing ran parallel to one another. The major issue identified at this stage was that the small sample size which result in: 1) not enough data to make decisions and a consensus; and 2) random data in acceptability depending on user groups. Depending on complexity of data, this phase could take long. Evaluating IoT system thoroughly was almost impossible without completing the product and service ecosystems.

4. Finalising the design and integrating and debugging the system

After testing feasibility and acceptability, and sensor development, a company is able to finalise their design, integrate, and debug the system. Developing digital artefact challenges the designer with a continual pressure of never being able to fix design and integrate system. This is due to one of the material properties of digitalised artefacts, programmability [37] which enables firms push new features to the customer on a regular basis. 
Over the past decades, keeping the design fluid is regarded as a primary challenge in NPD processes, increasing the time and/or cost required for project completion [49]. However, in IoT, this risk is more vulnerable due to the pace of innovation [37]. Due to the rapid pace of technology development, an old chip may no longer be available so that you have to procure a new chip which may result in redeveloping the system.

Another issue in the IoT system integration is the difficulty to have strategic alliances and to overcome the interoperability among different players. Because it is highly complex and often require strategic alliances with device manufacturers, software developers, or service providers. More products are connected and making bigger value constellation means there are likely to be more opportunities in value creation. However, with more partners getting involved in the value constellation, there is likely to be bigger risks if data leakage incidents arose.

\section{Procurement}

During the procurement phase of the IoT system development, it was recognised that special attention should be paid to issues around quality control. For example, problems in being unable to procure hardware components that can lead to the whole system having to be started again, new suppliers found, or the design being changed. If we refer back to our earlier discussion on value constellation, the larger this constellation is, the more vulnerable IoT systems development is in terms of procurement. Having constant and predictable quality of procurement is not a new issue as it is identified as the fifth of the most frequent risks in innovative NPD projects [50]. Prior to moving to the installation stage, there would normally be a recruitment, marketing and retail phase. However, within this discussion, it has been omitted as the process is based on the SPHERE project, which did not aim to commercialise the IoT products and services.

\section{Installation}

In the SPHERE project, the team did not have many issues regarding installation, as their system was not being commercialised. However, in the installation phase, small companies and start-ups should consider who installs the IoT devices. If qualified technicians are used, this will raise costs, and, as such, this could prove to be a risk to its overall success.

7. Monitoring and maintaining the IoT system

This stage is where user data and diagnostic data is collected on the products and services in order to evaluate and improve the IoT system. If a company build their own annotated data sets, they can start to test their AI algorithm within the IoT system.

8. Re-designing products and services based upon qualitative and quantitative evaluation

The final phase involves quantitative and qualitative evaluation of the system and users, and the value of IoT system would be defined and redefined. IoT is a multi-disciplinary area and the data you gather at this stage is generally outside of technology domain, for example, air quality, health, or energy consumption. Therefore, it is more than likely that external expert opinions will need to be obtained in order to generate insights from the data and again, building strong relationships with experts is very important. Through this phase, it is important to continue identifying customer requirements as well as redefining your value proposition. In this way, the IoT development process continues moving continuously through the phases in an iterative way.

The underlying development stages of process are not much different to existing NPD processes. However, the strategic development activities and the critical development risks are distinctive from traditional product development. Based on the NPD activities and issues of the SPHERE project a new NPD model for IoT products and services (Figure. 5) contains three distinctive phases:

- discover and define (1. identifying customers' requirements, 2. technical discussion),

- develop (3. testing feasibility and acceptability, and sensor development, 4. finalising the design and integrating and debugging the system), and

- deliver (5. procurement, 6. installation, 7. monitoring and maintaining the IoT system, 8. re-designing products and services based upon qualitative and quantitative evaluation methodologies).

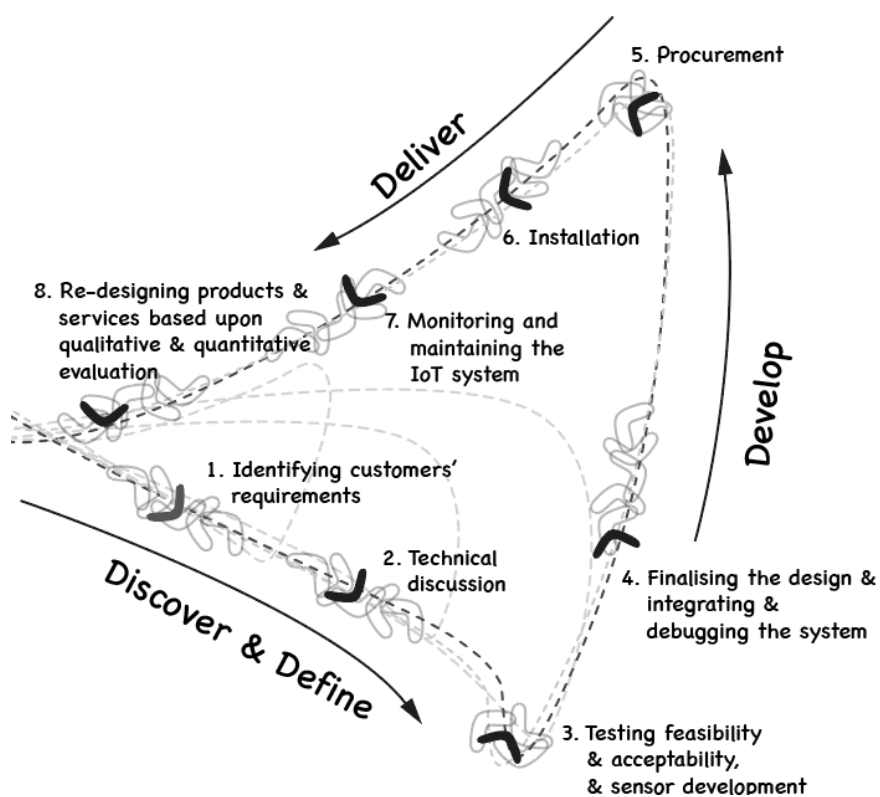

Fig. 5 A new NPD model for IoT products and services

The new model is not linear but continuous process which illustrate the trajectory of boomerang, an example of gyroscopic precession. The boomerang trajectory is used as a metaphor because once it flies in a curved path; it circles back toward the thrower who is the IoT company in this context. It could be related to IoT NPD process, as once IoT products and services are developed and installed, it generates data and brings it back to the company. Thus, the products and services can continuously evolve even after being launched and while being used. Moreover, the small spins of flying boomerang imply iteration of each stages of the process to step forward. This new approach towards NPD process for IoT is based on only one case study so it would be refined further in the future. The continuous and never-ending process cycle indicates that value propositions through IoT products and services are able to keep evolving for enhanced customer experiences. Moreover, as data enables organisations to collect an enormous amount of real-time information on customers' experience for 
current products, the pace of designing and improving the products and services should be shorter and faster. Data is not only changing design process but also the role of the designer(s). They no longer have to anticipate and develop generic products, with limited access to the data on customer needs as big data aids to acquire user and market information. Finally, the process has to become more complicated because unlike generating value in a linear value creation system, the spatial and temporal division between design, development, production, and consumption of offerings are increasingly collapsing into the same space, especially with changeable offerings informed by data [10].

\section{The critical risks over the NPD process were identified as} follows:

- challenging customers to articulate and define their requirements;

- being unable to test feasibility until sufficient data has been collected;

- $\quad$ never being able to complete the design;

- difficulties in maintaining IoT products and services;

- challenges in quality control;

- the unexpected increased time to completion;

- barriers in building the partnership within the whole eco-system; and risks in scaling-up and so forth

Considering the factors that affect IoT development and value creation, development risks in IoT is identified as more difficult to manage compared to the risks in traditional economy. This is because NPD activities in IoT tend to occur more externally and be affected by diverse variety of external risks such as: a hyper-accelerated innovation cycle of the evolution of IoT technologies (e.g., sensors, wireless technologies, and chips), challenges in co-working and communication with partners or suppliers, insufficient security, privacy, policies, regulations and standards.

In an unconnected world, a single device may have a minor problem, but for the IoT system as a whole, the chain reactions of other connected devices can become catastrophic [45]. Design, within this context, should not be treated in isolation from business processes but should be used more proactively and the risks should be more carefully managed throughout the value creation process.

\section{Conclusions (700)}

This research study offers a discussion of value creation in the traditional manufacturing economy and emergent digital economies the differences between the value chain model and a value constellation model. It also examines existing NPD models which are continuously evolving but not much improved to be applied to developing digitalised artefacts. This discussion identifies how the characteristics of big data and digital artefacts are related to NPD processes, product development risks, and value creation. The risks and processes for IoT development are then further elaborated and critically discussed through the case study.

1) How is traditional NPD processes and value creation different to its counterpart for IoT?
2) How are IoT products and services developed and what risks are found during the development process?

3) How can the product development risks be managed effectively?

The SPHERE project identified an eight-stage process for IoT products and services development in which risks and activities are likely to be more complicated than those of a traditional product; however, the basic progression of activities over the course of the process are similar to existing NPD processes. In essence, the design and development activities including risk management become more complicated and difficult to control. This is because the design of an IoT system is comprised of designing hardware, software, services and products. Software production and physical product production process are two completely different creation and operation models. Moreover, the process is done by different organisations. Thus, the multitude of stakeholders and the two different production process should be curated in terms of creating value for IoT.

Although this paper has explored the key challenges related to NPD process and value creation for IoT, there are a number of limitations that need to be taken into account through further research. Relying solely on a limited literature review and a single case study is limiting in terms of investigating the diverse variety of risks and their effective management. Moreover, the discussion of the SPHERE process is limited as their aim was not to commercialise the product but to understand the value and cost of acquiring data. As a result, the research team did not go through the whole process fully in a continuous and iterative way. Unlike small enterprises or startups, this was a government-funded project, which meant the team were least challenged by budget risks closely related to the product development process.

Related to the limitations of this study, the last research question is left for subsequent research. Within the NPD process risk management means that, the project manager has to be aware of what the risks are that might occur and when they might occur [51]. As this paper is mainly focused on identifying what are the development risks in IoT, with further research, the author(s) will collate more detailed data on how IoT organisations manage the risks over the design and development process.

\section{Acknowledgements}

The authors gratefully acknowledge the contributions of Professor. Ian Cradock at Bristol University toward this research paper, participating the research with insightful interview. This work is supported by EPSRC under the PETRAS project and RADMA doctoral funding.

\section{References}

[1] 'IEEE spectrum: Popular Internet of Things Forecast of 50 Billion Devices by 2020 is Outdated'

https://spectrum.ieee.org/tech-talk/telecom/internet/popularinternet-of-things-forecast-of-50-billion-devices-by-2020-isoutdated, accessed 17 January 2019 
[2] McKinsey Global Institute. 'Disruptive technologies: Advances that will transform life, business, and the global economy.' 2013

[3] Cisco. 'Embracing the Internet of Everything to Capture your share of \$14.4 Trillion.' 2013

[4] Porter, E, M. \& Heppelmann, E, J.: 'How Smart,

Connected Products Are Transforming Competition', Harvard

Business Review, Nov. 2014, pp.64-88

[5] Burkitt, F.: 'A Strategist's Guide to the Internet of Things: The digital interconnection of billions of devices is today's most dynamic business opportunity', PWC, Issue 77, Winter, 2014

[6] 'Cisco: The Journey to IoT Value: Challenges,

Breakthroughs, and Best Practices.'

https://www.slideshare.net/CiscoBusinessInsights/journey-toiot-value-76163389 accessed 18 January 2019

[7] 'Gartner: Gartner says the Internet of Things will transform the data center. Retrieved from

https://iot.do/gartner-says-internet-things-will-transform-datacenter-2014-03, accessed 14 July 2018

[8] Yoo, Y., Boland, J., Lyytinen, K. et al.: 'Organizing for innovation in the digitalized world'. Organization Science, 2012, 23(5), pp1398-1408.

[9] Hui, G.: How the Internet of Things Changes Business Models, Harvard Business Review. 2014

[10] Ng, C.L. I., Wakenshaw, Y.L. S.: 'The Internet of Things: Review and Research Directions', International Journal of Research in Marketing, 34 (2017) 3-21, pp. 4-21

[11] Speed, C., Maxwell, D.: 'Designing Through Value Constellations'. ACM Interactions Magazine, Sep- Oct, 2015, pp. 39-43

[12] Susterova, M., Lavin, J., Rives, J.: 'Risk Management in Product Development Process'. Annals of DAAAM for 2012 and Proceedings of the 23rd International DAAAM Symposium, vol 23. No 1.

[13] Smith, P.G., Merritt, G.M.: 'Proactive Risk Management - Controlling Uncertainty in Product Development',

Productivity Press, New York, 2002.

[14] Thauser, J.: 'Risk Management of New Product

Development', A Manual for SMEs. 9th IBA Bachelor Thesis

Conference. July 5th 2017. University of Twente, The Faculty of Behavioural, Management and Social sciences.

[15] Leithold, N., Woschke, T., Haase, H., et al.: 'Optimising NPD in SMEs: a best practice approach. Benchmarking', An International Journal, 23(1), pp 262-284.

[16] Teller, J., Kock, A., Gemünden, H. G.: 'Risk management in project portfolios is more than managing project risks: A contingency perspective on risk management'. Project Management Journal, 45(4), 67-80.

[17] Smith, P.G., Merritt, G.M.: 'Proactive Risk Management - Controlling Uncertainty in Product Development',

Productivity Press, New York, 2002.

[18] Grit, R.: Project Management- A practical approach

(Fourth ed.). Groningen: Noordhoff Uitgevers bv

Groningen/Houten

[19] Hillson, D.: 'Use a Risk Breakdown Structure (RBS) to understand risks', Proceedings of the Project

Management Institute Annual Seminars \& Symposium, San Antonio, USA, 2002.
[20] Skec, S., Storga, M., Marjanovic, D.: 'Mapping Risks on Various Product Development Process Types'. Transactions of Famena. XXXVII-3, 2013

[21] Ulrich, K. T., Eppinger, S. D.: 'Product Design and Development'. (Boston: McGraw-Hill, 2011)

[22] Porter. M., Millar, V.: 'How Information Gives you Competitive Advantage'. Harvard Business Review. 1985. 63(4): 149-160.

[23] Andreassen, T., Kristensson, P., Lervik-Olsen, L., et al.: 'Linking service design to value creation and service research', Journal of Service Management, 2016. 27 (1), pp. 21-29

[24] Trott, P.: 'Innovation Management and New Product Development' (5th Ed.). (London: Person Education, 2012)

[25] Clark, Kim B. (1989), "Project Scope and Project Performance: The Effect of Parts Strategy and Supplier Involvement on Product Development," Management Science, 35 (October), 124-63.

[26] Takeuchi, H., \& Nonaka, I. (1986). The new Conduct Development Game, Harvard Business Review Jannuary/February: 137-146.

[27] Pennell, P. J., Winner, I. R., Bertrand, E. H., et al.: 'Concurrent engineering: An overview for Autotestcon', IEEE Automatic Testing Conference Proceedings, 1989, pp.88-99.

[28] Crawford, C. M.: 'New Products Management (5th Ed.)'. (McGraw-Hill, Inc., 1997)

[29] Hart, S. J., Baker, M. J.: 'The Multiple Convergent Processing Model of New Product Development'.

International Marketing Review, 1994, 11 (1), pp 77-92.

[30] Evans, B.: 'Japanese-style management, product design and corporate strategy', Design Studies, 1985, 6(1), pp25- 33 [31] Design Council: 'Eleven Lessons: Managing Design in Eleven Global Companies (Desk Research Report)', 5th November 2007.

[32] Johnson, S. P., Menor, L. J., Chase, R. B., et al.: 'A critical evaluation of the new services development process: integrating service innovation and service design', in Fitzsimmons, J.A. and Fitzsimmons, MJ. (Eds), New Service Development Creating Memorable Experiences. (Thousand Oaks, CA: Sage Publications, 2000)

[33] Chesbrough, W. H.: 'Open Innovation: Renewing Growth from Industrial R\&D', 10th Annual Innovation Convergence, Minneapolis, 27th September 2004.

[34] Beck, K., Beedle, M., van Bennekum, A., et al.: 'Manifesto for Agile Software Development'.

http://agilemanifesto.org/, accessed on $15^{\text {th }}$ May 2018.

[35] Wind, J., Mahajan, V.: 'Issues and Opportunities in New Product Development': An Introduction to the Special Issue. Journal of Marketing Research. Vol. XXXIV (Feb, 1997), pp1-12.

[36] Henfridsson, O., Mathiassen, L., \& Svahn, F. (2014). Managing technological change in the digital age: The role of architectural frames. Journal of Information Technology, 29(1), 27-43.

[37] Yoo, Y., Lyytinen, K. J., Boland, R. J., Jr., et al.: 'The next wave of digital innovation: Opportunities and challenges.' A report on the research workshop 'digital challenges in innovation research.' 2010. 
[38] Chan, H. (2015) Internet of Things Business Models, Journal of Service Science and Management, 2015, 8, pp. $552-568$

[39] McAfee, A., Brynjolfsson, E.: 'Big data: The management revolution'. Harvard Business Review. 2012, 90 (10): pp 60-68.

[40] Mejtoft, T.: 'Internet of Things and Co-creation of Value'. IEEE International Conferences on Internet of Things, and Cyber, Physical and Social Computing. 2011 [41] Michel, S.: 'Innovative Werkonstellationen.

Handelszeitung'. 2009, http://bit.ly/1PlCNAB, accessed $29^{\text {th }}$ December, 2017

[42] Wind J., and Mahajan, V. (1997) Issues and Opportunities in New Product Development: An Introduction to the Special Issue. Journal of Marketing Research. Vol. 34

(1) pp. 1-12

[43] Lusch, R. F., Vargo, S. L.: 'The service-dominant logic of marketing: Reactions, reflections, and refinements'. Marketing Theory, 2006, 6(3), pp 281-288.

[44] Michel, S., Vargo, S., Lusch, R.: 'Reconfiguration of the conceptual landscape: A tribute to the service logic of Richard Norman'. Journal of the Academy of Marketing Science. 2008, 36, pp 152-155

[45] Lee, I., Lee, K.: 'The Internet of Things (IoT):

Applications, Investments and challenges for enterprises'. Business Horizons, 2015, 58(4), pp 431-440

[46] Speed, C.: 'New Product Development, Business Process and Strategy in IoT'. Interview by Boyeun lee, Skype, 21st October 2017.

[47] Davis, N.: 'New Product Development, Business Process and Strategy in IoT'. Interview by Boyeun Lee, in person, 24th October 2017.

[48] Burrows, A., Gooberman-Hill, R., Coyle, D.: 'Home truths: Insights for designing inclusive smart home technologies for healthcare'. Design4Health European Conference. 2015

[49] Gil, N., Tether, B.: 'Project risk management and design flexibility: Analysing a case and conditions of complementarity'. Research policy 40 (2011) pp 415-428. [50] Keizer, J. A., Halman, J. I. M.: 'Risks in major innovation projects, a multiple case study within a world's leading company in the fast-moving consumer goods'. International Journal of Technology Management, June 2009, 48(4): 499-517

[51] Keizer, J., \& Vos, J.-P. (2003). Diagnosing risks in new product development. Eindhoven Centre for Innovation Studies. 